Rev. Hist., N 26, vol. 1, Enero-junio 2019: 7 - 28

ISSN 0717-8832

\title{
Cicatrices en el alma. Las consecuencias emocionales de la experiencia bélica de los combatientes chilenos de la guerra del pacífico (1879-1884).
}

Scars on the soul. The emotional consequences of the belief experience of the Chilean

fighters of the War of the Pacific (1879-1884).

Cristián González Puebla*

\section{RESUMEN}

En los algunos de los relatos que dejaron combatientes chilenos de la Guerra del Pacífico, y que han sido publicados desde fines del conflicto hasta el presente, quedaron plasmadas las consecuencias emocionales que experimentaron estos y sus compañeros durante el conflicto y para el resto de sus vidas. Estas consecuencias derivan de que quienes dejaron un relato de sus vivencias son parte de una misma comunidad emocional, y para poder acercarnos a estas, los estudios sobre la memoria permiten reconocer en las narraciones de los combatientes fragmentos, silencios y olvidos.

Palabras claves: Consecuencias emocionales, Guerra del Pacífico, Combatientes, Memoria, Testimonios.

\section{ABSTRACT}

In some of the testimonies left by Chilean fighters of the Pacific War, which have been published since the end of the conflict to the present, the emotional consequences experienced by them and their companions during the war and the rest of their lives were captured. These consequences derive from the fact that those who left an account of their experiences are part of the same emotional community. To be able to approach them, the studies on memory allow to recognize in the narrations of the combatants fragments, silences and forgetfulness.

Key Words: Emotional consequences, War of the Pacific, Fighters, Memory, Testimonies.

Recibido: agosto 2018

Aceptado: marzo 2019

\footnotetext{
* Licenciado en Historia y Magíster en Historia de Chile y de América por Universidad de Valparaíso. Funcionario Universidad de Playa Ancha de Ciencias de la Educación. (Chile).E-mail: gonzacristian@gmail.com.
} 


\section{Introducción}

Desde comienzos del siglo XXI el estudio de la Guerra del Pacífico (1879-1884) se ha revalorizado en Chile. Diversas investigaciones acerca de este conflicto, que enfrentó a nuestro país con Perú y Bolivia, han comenzado a abordar temáticas, actores y fuentes que la historiografía tradicional no consideró. El estudio de las relaciones internacionales durante la Guerra $^{1}$, de las mujeres ${ }^{2}$, de los veteranos ${ }^{3}$, a la vez que diversos acercamientos al tema desde lo social y lo cultural ${ }^{4}$, han abierto nuevas interrogantes en una temática que no parece agotarse para la historiografía chilena. Asimismo, los historiadores peruanos también han realizado grandes aportes al estudio de este conflicto, como es el caso de Carmen Mc Evoy y

\footnotetext{
${ }^{1}$ Véase los trabajos de Claudio Tapia y Mauricio Rubilar: Respecto al primer autor, sus últimas obras en relación a esta temática son: Tapia, C. 2017. "La política chilena en la postguerra del Pacifico: poder, influencia y relaciones con Ecuador", Revista Historia Crítica. N64, pp. 121-139; Tapia, C. 2018. "Intereses, rivalidades y consecuencias. Una reflexión sobre la guerra en el Pacífico Sudamericano", en Chaupis, J. y Tapia, C. (Edit.), La Guerra del Pacífico 1879-1884: ampliando miradas en la historiografía chileno- peruana. Santiago. Legatum Editores. pp. 19-40; Tapia, C. 2018. "La construcción de la política exterior chilena en el contexto de la guerra y postguerra del Pacífico", en Ibarra, P. y Morong, G. (Edit.), Relecturas de la Guerra del Pacífico. Avances y perspectivas. Santiago. Ediciones Universidad Bernardo O'Higgins, pp. 145-170.

Respecto al Mauricio Rubilar, sus últimos trabajos son: Rubilar, M. 2015.“'La Prusia Americana': prensa argentina e imaginario internacional de Chile Durante la Guerra del Pacífico", Revista de Historia y Geografía. N³3, pp. 83-121; Rubilar, M. 2017 "Prensa, opinión pública y política exterior de Chile durante la Guerra del Pacífico (1879-1883)", en Díaz, A., González, S., Ruz, R., Salazar, P. (Edit.), WAYRA. Nuevos vientos en la historiografía chilena, Ediciones Universidad de Tarapacá, pp. 321-336; Rubilar, M. 2018. "El bárbaro del Pacífico: imaginario discursivo sobre Chile en la prensa de Buenos Aires durante la Guerra del Pacífico 1879-1881", en Chaupis, J. y Tapia, C. (Edit.), La Guerra del Pacífico 1879-1884: ampliando miradas en la historiografía chileno- peruana. Santiago. Legatum Editores. pp. 67-92.

${ }^{2}$ Véase Larraín, Paz. 2006. La presencia de la mujer chilena en la Guerra del Pacífico, Santiago, Universidad Gabriela Mistral.

${ }^{3}$ Véase Méndez N., C. 2009. Héroes del Silencio: los veteranos de la Guerra del Pacífico (1884-1924), Santiago, Centro de Estudios Bicentenario; 2009. Desierto de esperanzas: de la gloria al abandono. Los veteranos chilenos y peruanos de la guerra del 79. Santiago, Centro de Estudios Bicentenario; 2013. Dolor y olvido: los ex combatientes bolivianos de la Guerra del Pacífico, Santiago, Centro de Estudios Bicentenario.

${ }^{4}$ Al respecto, véase entre otros: Cid, G.2011 "Arte, Guerra e Imaginario Nacional: la Guerra del Pacífico en la pintura de Historia chilena, 1879-1912", en Donoso C. y Serrano G. (Eds.), Chile y la Guerra del Pacífico. Santiago Centro de Estudios Bicentenario. pp. 75-113; Rubilar, M. 2018, "iLos hijos del Biobío en pie de guerra!: Iglesia, prensa y compromiso ciudadano durante la Guerra del Pacífico (1879-1881)", en Ibarra, P. y Morong G (Eds.), Relecturas de la Guerra del Pacífico. Avances y perspectivas. Santiago, Editorial Universidad Bernardo O'Higgins, pp.49 -72; Veliz, C. 2015. "Bajo la tienda (1958): la representación subalterna del "roto" como fundamento de la nacionalidad para el siglo XIX chileno". Dialogo Andino. N48. pp. 7-17.

${ }^{5}$ Véase Mc Evoy, C. 2010. Armas de persuasión masiva: retórica y ritual en la Guerra del Pacífico. Santiago, Centro de Estudios Bicentenario; 2013. Guerreros Civilizadores. Política, Sociedad y Cultura en Chile durante la Guerra del Pacífico. Santiago, Ediciones Universidad Diego Portales; 2016. Chile en el Perú. La ocupación a través de sus documentos, 1881-1884. Lima, Fondo Editorial del Congreso del Perú. Entre otros.
} 
José Chaupis ${ }^{6}$, por mencionar algunos. Investigadores de ambos países han realizado esfuerzos comunes para estudiar el tema, y han realizado publicaciones conjuntas ${ }^{7}$.

Ahora bien, en lo estrictamente bélico, a lo que ataña al campo de batalla y a las campañas militares, también se ha dado un importante desarrollo, siendo obras como "Problemática del Soldado durante la Guerra del Pacífico" ${ }^{8}$ de Sergio Rodriguez Rautcher o "Tragedia Andina. La lucha en la Guerra del Pacífico (1879-1884)" Además, valiosos segmentos de trabajos realizados por historiadores se refieren a lo que sucede en la Guerra en sí misma, en el enfrentamiento desatado. Al respecto, la novedosa investigación de Patricio Ibarra "La Guerra en Cautiverio. Los prisioneros de la Guerra del Pacífico (1879-1884) ${ }^{10}$, entrega antecedentes respecto al llamado "repase", el cual consistió en dar muerte a los soldados heridos y que no se encontraban en condiciones de luchar durante los combates ${ }^{11}$. Del mismo modo, el interesante artículo de Patricio Rivera Olguin "Fantasmas de rojo y azul. Los saqueos de las tropas chilenas en la guerra del Pacífico" ${ }^{12}$, contribuye a analizar el pillaje cometido por los soldados chilenos tras los combates.

Reconociendo y valorando estas investigaciones, este artículo busca resaltar las consecuencias emocionales experimentadas por los combatientes chilenos al verse sometidos ante situaciones extremas, tanto en los campos de batalla como en las campañas de la Guerra. Nuestra historiografía se ha esforzado mucho en lograr ampliar el estudio de la Guerra en las más diversas facetas, pero consideramos que las investigaciones de las batallas y la experiencia en las campañas militares en sí mismas no han tenido la misma capacidad de renovación que los otros ámbitos destacados más arriba, siendo dejada de lado por la academia y solo estudiada por aficionados y militares. Pareciendo, como señala el historiador

\footnotetext{
${ }^{6}$ Véase Chaupis, J. 2015. “Guerra del Pacífico y Construcción de la Justicia: los procesos penales en Lima durante la ocupación chilena", Revista de Historia y Geografía. N³3, pp.63-82; 2015. "Los textos escolares en conflicto con la subalternidad: la Guerra del Pacífico en las Aulas". Dialogo Andino. №48. Pp. 99-108. Entre otros.

${ }^{7}$ Véase entre otros: Donoso C. y Serrano G. (Eds.) 2011. Chile y la Guerra del Pacífico. Santiago. Centro de Estudios Bicentenario.

Cavieres E. y Chaupis J. (Eds.) 2015. La Guerra del Pacífico en perspectiva histórica: reflexiones en pasado y en presente. Antofagasta. Universidad de Tarapacá.

Ibarra, P. y Morong, G. (Edit.). 2018. Relecturas de la Guerra del Pacífico; Chaupis, J. y Tapia, C. (Edit.). 2018. La Guerra del Pacífico 1879-1884.

${ }^{8}$ Rodríguez R., S. 1986. Problemática del soldado durante la Guerra del Pacífico. Santiago, Edimpres.

${ }^{9}$ Veáse Satter., W. 1986. Chile and de War of the Pacific. Lincoln. University of Nebraska; 2007. Andean Tragedy: Fighting the War of the Pacific (1879-1884). Lincoln. University of Nebraska. Obra traducida el año 2016 como Tragedia Andina: La lucha en la Guerra del Pacífico (1879-1884). Santiago, Centro de Investigaciones Barros Arana.

10 Ibarra C., P. 2017. La guerra en cautiverio. Los prisioneros de la Guerra del Pacífico (1879-1884). Santiago. Legatum Ediciones.

${ }^{11}$ Ibídem. p. 17.

12 Rivera O. P. 2016. "Fantasmas de rojo y azul. Los saqueos de las tropas chilenas en la guerra del Pacífico", en Anuario Colombiano de Historia Social y de la Cultura, Vol. 43, №1, Bogotá, p. 263-293.
} 
argentino Alejandro Rabinovich en su obra "La Anatomía del Pánico: La batalla de Huaqui o la derrota de la Revolución (1811)", al reflexionar sobre lo que ocurre en su país, que: "[...] lo que sucede una vez que comienzan los tiros no se estudia, como si esas pocas horas de brutalidad que representan las batallas no hubieran tenido verdadera incidencia sobre los grandes procesos históricos y sociales ${ }^{13 \prime \prime}$.

Al destacar las consecuencias emocionales experimentadas por los combatientes durante y tras la Guerra entramos en un espacio íntimo y brutal a la vez. El horror del conflicto, muy lejano a los uniformes, los estandartes y las marchas militares aflora, convirtiendo a los hombres y mujeres que sobrevivieron en portadores de una experiencia que el resto de las generaciones de chilenos no ha vivido, una guerra internacional. Quienes sobrevivieron no quedaron solo con cicatrices o marcas en sus cuerpos, pasando muchos de ellos toda clase de penurias económicas y demandando del Estado asistencia económica. También quedaron cicatrices en el interior de los sujetos. Al referirnos a las consecuencias emocionales, nos derivamos a un concepto propio de la Historia de las Emociones ${ }^{14}$, tendencia historiográfica que ha tenido un gran auge desde fines del siglo XX. Nos referimos al de "Comunidad Emocional", el cual fue acuñado por la historiadora norteamericana Barbara Rosewein, quien lo definió como: "grupos en los cuales las personas se adhieren a las mismas normas de expresión emocional y valoran -o desvirtúan- emociones iguales o relacionadas" ${ }^{15}$. Esta noción se asocia fuertemente al concepto de comunidad social, lo que permite una gran versatilidad para estudiar a distintos grupos humanos de distintos tamaños, a la vez que los sujetos pueden moverse entre distintas comunidades emocionales ${ }^{16}$.

Con esto señalado, la comunidad emocional a la que atenderemos será aquella compuesta por los hombres y mujeres del "Ejército del Norte" durante la Guerra del Pacífico y que hayan

\footnotetext{
13 Rabinovich, Alejandro. 2017. Anatomía del pánico: La batalla de Huaqui, o la derrota de la Revolución (1811), Buenos Aires, Editorial Sudamericana.

${ }^{14}$ La Historia de las Emociones es una tendencia historiográfica que ha tenido un notable desarrollo a nivel internacional desde fines de los años noventa del siglo recién pasado, siendo sus exponentes más importantes Peter Stearns, Carol Stearns, Barbara Rosewein y William Reddy. En el mundo hispano se destaca Javier Moscoso, y en nuestro país Pablo Toro Blanco, María Eugenia Albornoz, entre otros. Respecto a mayores antecedentes sobre la Historia de las Emociones, véase:

Zaragoza Bernal, J. 2013. "Historia de las emociones una corriente historiográfica en expansión", en Revista de Historia de la Medicina y de las Ciencias. Vol. 65, N¹. CSCIC.

Moscoso, J. 2015. “La Historia de las Emociones ¿De qué es Historia?”, en Vínculos de Historia. №4. pp. 15-27. Pampler, Jan. 2014. "Historia de las Emociones: Caminos y retos", en Cuadernos de Historia Contemporánea. Vol. pp-.17-29.

15 "I postúlate the existence of 'emotional communities': groups in wich people adhere to the same norms of emotional expression and value- or devalue- the same related emotions". Rosewein, B. H. 2006. Emotional Communities in the early middle ages. Ithaca, NY. Cornell University Press. p.2.

${ }^{16}$ Medina Brener, L. 2015. "Comunidades emocionales: hacia la apertura de la historia de las emociones". En Historia y Grafía. Año 22. №45. Pág. 207.
} 
estado inmersos en el fragor del combate y las campañas militares. No importa, para efectos de esta aproximación, el rango que hayan tenido los combatientes durante la guerra ni la clase social a la que pertenecían. Después de todo, tanto en la penuria de las marchas como en el caos de la batalla, entre los gritos de los heridos y el miedo a morir eso parece disolverse, quedando solo la experiencia en común. Asimismo, cabe recalcar que al analizar las consecuencias emocionales no nos referimos a las eventuales patologías mentales que debieron haber experimentado algunos de los combatientes, y posteriormente veteranos de la Guerra del Pacífico. Esto requeriría de una investigación con otras fuentes y de carácter interdisciplinar.

Ahora bien, en este artículo destacaremos las consecuencias emocionales de la experiencia bélica que han sido plasmados en algunos de los testimonios, crónicas o diarios de combatientes chilenos, y que fueron publicados tanto inmediatamente después de la guerra como durante el siglo XX y XXI; hubiesen o no tenido voluntad los autores de publicar sus escritos. No nos acercaremos a los testimonios dejados por sacerdotes como Ruperto Marchant ${ }^{17}$ o a los de periodistas como Eloy Caviedes ${ }^{18}$ y Daniel Riquelme, tampoco a los de extranjeros como Ackland $^{19}$ o de políticos como José Francisco Vergara ${ }^{20}$. De igual forma, tampoco consideraremos las cartas dejadas por los combatientes.

Los testimonios de los combatientes no son demasiados, y consideraremos lo relatado en pasajes de seis de los escritos publicados. Esto debido a que en ellos se pueden apreciar claramente las consecuencias emocionales. Estos son: "Diario de Campaña. Recuerdos íntimos de la Guerra del Pacífico" ${ }^{21 "}$, de Alberto del Solar (1859-1921); "Seis años de Vacaciones. Recuerdos de la Guerra del Pacífico $22 "$, de Arturo Benavides Santos (1864-1937); "Diario de Campaña. Lo que yo he visto"23, de Diego Dublé Almeida (1841-1922); “Memorias Militares"24",

\footnotetext{
${ }^{17}$ Marchant Pereira, R. 2004.Testimonios de un capellán castrense en la Guerra del Pacífico, estudio preliminar de Paz Larraín y Joaquín Matte Varas, Santiago, Centro de Estudios Bicentenario.

18 Veáse Castagneto, P. 2014. Eloy Caviedes. Cartas de la escuadra: la campaña naval de 1879 relatada por el corresponsal de "El Mercurio", Santiago, Red Internacional del Libro; 2007. Eloy Caviedes: El combate de lquique. Viña de Mar, Ediciones Altazor.

19 Ibarra, P. 2007. "Un testimonio sobre la entrada del Ejército chileno a Lima (Enero de 1881). Cuadernos de Historia. $\mathrm{N}^{\circ} 26$. pp. 171-186.

${ }^{20}$ Ruz Trujillo, F. (comp) Vergara, J. F. (1833-1889); Dublé Almeida, D. (1841-1922). 1979. Guerra del Pacífico, Santiago, Editorial Andrés Bello.

${ }^{21}$ Del Solar, A. 1967. Diario de campaña: recuerdos íntimos de la Guerra del Pacífico: 1879- 1884, Buenos Aires, Editorial Francisco de Aguirre.

${ }^{22}$ Benavides S. A. 1929. Seis años de Vacaciones. Recuerdos de la Guerra del Pacífico. 1879-884, Santiago, Imprenta Ahumada.

${ }^{23}$ Los recuerdos de Diego Dublé Almeida han sido publicados de forma fragmentaria. Una parte fue presentada en 1968 por la Revista Chilena de Historia y Geografía con el título "La jornada de Tacna. Un cuadro de Campaña" (Dublé Almeida, D. 1968. "La jornada de Tacna. Un cuadro de campaña”, en Revista Chilena de Historia y Geografía,
} 
de Estanislao del Canto (1840-1923); "Impresiones y recuerdos sobre la Campaña al Perú y Bolivia ${ }^{25 "}$, de José Clemente Larraín (1857-1931). Y finalmente, el diario de campaña de Justo Abel Rosales (1855-1896), llamado “Mi Campaña al Perú. 1879-1881"26". Todos estos escritos no son inéditos para la historiografía chilena y varios de ellos han sido citados en diversas publicaciones.

De igual manera, existen varios relatos publicados aparte de los mencionados más arriba. Al respecto, podemos mencionar el del soldado Marcos Ibarra ${ }^{27}$, que es uno de los pocos que existen respecto a la campaña de la Sierra o la Breña. El de Hipólito Gutiérrez, que junto a las cartas de Abraham Quiroz tuvo una gran difusión en la segunda mitad del siglo $\mathrm{XX}^{28}$. A estos se suma lo escrito por Antonio Urquieta ${ }^{29}$, Guillermo Chaparro ${ }^{30}$, Evaristo Sanz ${ }^{31}$, Lucio Venegas ${ }^{32}$ y Genaro Silva Prado ${ }^{33}$. A la vez que los testimonios conocidos en las últimas décadas, como los de Arturo Olid ${ }^{34}$, José Ramón Lira $^{35}$ y de José Miguel Varela, este último adaptado y recopilado por Guillermo Parvex en el libro "Un veterano de tres guerras" ${ }^{36}$.

$\mathrm{N}^{\circ} 136$, 1968. pp. 125-168.). Otro fragmento fue publicado por Fernando Ruz Trujillo en 1979 junto con las Memorias de José Francisco Vergara (Ruz Trujillo, F (comp.). 1979. Guerra del Pacífico.) y finalmente, entre los años 2011 y 2012 fue publicado integro en los Cuadernos de Historia Militar gracias a la labor realizada por Patricio Ibarra y Sergio Villalobos (Dublé Almeida, D. "Diario de las Campañas al Perú y Bolivia. 1879-1884. Lo que yo he visto" 2011, 2012. En Cuadernos de Historia Militar. N 7 pp. 23-92 y N8 7-60).

24 Del Canto, E. 2004. Memorias Militares. Edición y Estudio preliminar de Alejandro San Francisco, Santiago, Centro de Estudio Bicentenario.

${ }^{25}$ Larraín, J. C. 2007. Impresiones y recuerdos sobre la Campaña al Perú y Bolivia, Santiago, Centro de Estudios e Investigaciones Militares.

${ }^{26}$ Rosales, J. 1984. Mi Campaña al Perú (1879-1881). Concepción. Universidad de Concepción.

${ }^{27}$ Ibarra Díaz, M. 1985. Campaña de la Sierra: La Concepción - una aventura. La Serena, Universidad de La Serena.

${ }^{28}$ Gutiérrez, H. y Quiroz, A. 1976. Dos soldados en la Guerra del Pacífico, Buenos Aires, Editorial Francisco de Aguirre.

29 Urquieta, A. 1907. Recuerdos de la vida en campaña en la Guerra del Pacífico. Santiago, Escuela Talleres "Gratitud Nacional".

${ }^{30}$ Chaparro W., Guillermo. 1910. Recuerdos de la Guerra del Pacífico. Santiago. S/N.

${ }^{31}$ Sanz, E. 1883. Hojas sueltas de mi diario de campaña, o reminiscencias de la Guerra del Pacífico: 1879, Santiago, Imprenta de la Librería Americana

32 Venegas, L. 1885. Sancho en la Guerra: Recuerdos de la campaña del Ejército al Perú y Bolivia, Santiago, Imprenta Victoria.

33 Silva Prado, G. 1926. Memorias del veterano, Santiago, Imprenta "La Economía".

34 Olid Araya. A. 1999. Crónicas de Guerra: relatos de un ex combatiente de la Guerra del Pacífico y la Revolución de 1891. Santiago. Ril Editores.

35 Lehnert, Roberto. y Lira Calderón. José., 2010. Vivencias de un héroe: Capitán José Ramón Lira en la Guerra del Pacífico, Antofagasta, Instituto de Investigaciones Antropológicas.

36 Parvex, G. 2014. Un veterano de tres guerras. Recuerdos de José Miguel Varela, Santiago, Academia de Historia Militar. 
En la mayoría de los relatos los autores enaltecen la imagen pública de sí mismos y sus compañeros de armas, narrando situaciones de gran valor individual y colectivo, a la vez que se lamentan de la guerra y las consecuencias de ella tanto en lo humano como en lo material $^{37}$. De igual forma, constantemente se omiten situaciones embarazosas o que no apuntan a la construcción de un relato heroico, siendo un ejemplo de ello la omisión deliberada en varios de los relatos del saqueo y destrucción de Chorrillos y Mollendo ${ }^{38}$. Por otra parte, estos testimonios fueron construidos en distintas etapas de la vida de los sujetos. Algunos fueron escritos pasados apenas unos días después de las combates, como es el caso del relato de las batallas de Chorrillos y Miraflores de Justo Abel Rosales. En otros, a unos cuantos años, como en el de Alberto del Solar, o décadas, como en los de Arturo Benavides Santos o el de José Clemente Larraín. Asimismo, los móviles para escribir varían, como veremos más adelante.

También, cabe considerar, como señala Patricio Ibarra, que solo una fracción de los combatientes chilenos sabían leer y escribir, por lo cual la cantidad de testimonios dejados por ellos es escasa. Este autor indica que para el censo de 1875: [...]“la proporción de chilenos que dominaban la escritura era de 1 cada 4,9 personas, incluyendo hombres y mujeres sobre un total de 2.075.971 habitantes" ${ }^{39}$.

A partir de lo anterior, cabe preguntarse: ¿Cómo acercarnos a las consecuencias emocionales plasmadas en los relatos de los combatientes? ¿Cómo comprender ese espacio tan íntimo y profundo de un sujeto que ya no está presente? Al respecto, debemos reconocer que al destacar las consecuencias emocionales entramos en un espacio en donde la subjetividad está presente al momento de hacer un ejercicio interpretativo, entendiendo tal como lo señala la historiadora norteamericana Joann Scott que: "La historia se encuentra en la posición paradójica de crear los objetos que declara solo descubrir. Por crear no quiero decir aparecer las cosas, sino más bien construirlas como objetos de conocimiento legítimos y coherentes $^{\prime 40}$. Esta reflexión lleva a reconocer la complejidad de la labor historiográfica, ya que manteniendo el rigor científico se debe reconocer la subjetividad que reporta el empeño interpretativo, apoyándose siempre en los vestigios del pasado. De igual forma, para poder acercarnos a las consecuencias emocionales producidas por la experiencia bélica que vivieron los combatientes chilenos de la Guerra del Pacífico, los estudios sobre la memoria cobran un

\footnotetext{
${ }^{37}$ Ibarra, P. 2018. "'Narro lo que vi': la Guerra del Pacífico en primera persona”, en Chaupis, J. y Tapia, C. (Edit.), La Guerra del Pacífico 1879-1884: ampliando miradas en la historiografía chileno- peruana. Santiago,Legatum Editores, págs. 220 y 223.

${ }^{38}$ El saqueo y destrucción de Chorrillos se produjo el 13 de enero de 1881 tras la batalla del mismo nombre y el de Mollendo entre los días 10 y 12 de marzo de 1880, en el contexto de la campaña a Tacna y Arica.

39 Ibarra, P. 2018. "Narro lo que vi...". p. 219.

${ }^{40}$ Wallach Scott, J. 2014. “¿Después de la Historia?”, Rey Desnudo. Revista de Libros Año II. Nº. p. 6.
} 
rol relevante. Estos estudios, que principalmente se asocian a investigaciones acerca de la historia del tiempo presente y a las traumáticas situaciones vividas por víctimas de violaciones a los Derechos Humanos durante las Dictaduras militares presentes en América Latina durante los años setenta, como así también a las víctimas del Holocausto durante la Segunda Guerra Mundial, tienen su origen en la obra del sociólogo francés Maurice Halbachws (1877-1945). Siendo Elizabeth Jelin una de las investigadoras más destacadas sobre los estudios sobre la memoria en el Cono Sur. En su libro "Los trabajos de la memoria" ${ }^{\prime 1}$, indica algunos elementos que permitirán acercarse adecuadamente tanto a la labor interpretativa como a las características de los testimonios, para poder así resaltar las consecuencias emocionales experimentadas por los combatientes chilenos.

Por un lado, Jelin indica que la propia experiencia, en el caso presentado aquí, el haber sobrevivido a la Guerra del Pacífico: [...] "interviene de manera central en lo que el sujeto

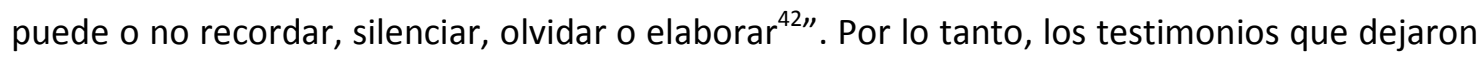
los combatientes chilenos tienen un carácter fragmentario, en el que hay olvidos y silencios. La autora trasandina señala a su vez que: "Toda narrativa del pasado implica una selección. La memoria es selectiva: la memoria total es imposible." ${ }^{43}$ Junto con esto, es importante destacar, tal como se indicó anteriormente, que varios de los relatos fueron escritos muchos años después de terminada la guerra. Esto implica que los recuerdos estuvieron incorporados en la vida de los veteranos "pero de manera dinámica, ya que las experiencias incorporadas en un momento dado pueden modificarse en momentos posteriores ${ }^{44 \prime}$.

Otro aspecto importante a señalar que indica Elizabeth Jelin, sobre todo respecto a las eventuales suspicacias que puedan generar los relatos, y que a su vez se relaciona con el concepto de comunidad emocional es el que: “[...] las memorias son simultáneamente individuales y colectivas, ya que en la medida en que las palabras y la comunidad de discurso son colectivas, la experiencia también lo es. Las vivencias individuales no se transforman en experiencias con sentido sin la presencia de discursos culturales, y estos son siempre colectivos. $^{45 \prime \prime}$

Por consiguiente, habiendo señalado todo lo anterior, podemos sostener que en algunos de los relatos que dejaron combatientes chilenos de la Guerra del Pacífico, y que han sido publicados desde fines del conflicto hasta el presente, quedaron plasmadas las consecuencias emocionales que experimentaron ellos y sus compañeros durante el conflicto y el resto de sus

\footnotetext{
41 Jelin, E. 2001. Los trabajos de la memoria. Madrid. Siglo XXI Editores.

42 Ibíd., 10-11.

43 Ibíd., 29.

${ }^{44}$ Ibíd., 13.

45 Jelin, E. 2001. “Historia, memoria social y Testimonio”. En Iberoamericana. Año I, №1., p. 91.
} 
vidas. Estas consecuencias derivan de que quienes dejaron un relato de sus vivencias son parte de una misma comunidad emocional, en la cual las personas aceptan las mismas normas de expresión emocional y aceptan o rechazan emociones iguales o parecidas. Ahora bien, para acercarnos a estas consecuencias emocionales, los estudios sobre la memoria permiten reconocer en las narraciones de los combatientes fragmentos, silencios y olvidos.

Dividiremos este artículo en dos apartados, en el primero se buscará resaltar tanto la intensidad de la experiencia bélica que tuvieron los combatientes como la consecuencia emocional fundamental plasmada en los testimonios dejados por estos. En el segundo, nos acercaremos a consecuencias emocionales de diversa índole suscitadas durante la guerra misma, tales como aquellas que llevaron al suicidio, al colapso nervioso o a impresiones profundas tras la batalla en los combatientes chilenos, a la vez que distinguiremos los silencios, fragmentos y olvidos presentes en las narraciones de quienes dejaron testimonio.

\section{La intensidad de la experiencia bélica de los combatientes chilenos en la Guerra del Pacífico}

Como indicamos más arriba, los combatientes chilenos que dejaron relatos de sus vivencias en la Guerra del Pacífico no son demasiados. En su mayoría fueron oficiales de bajo rango durante el conflicto, con algunas excepciones, como Hipólito Gutiérrez o Marcos Ibarra, que eran simples soldados, o Estanislao del Canto, quien fue un oficial de alto rango a cargo de una cantidad importante de soldados. Todos tenían un nivel educacional relativamente alto para su época, y varios de ellos poseían ciertas conexiones sociales que les permitían tener alguna vinculación con la vida pública, sea esto publicando artículos en la prensa como en el caso de Arturo Olid o participando en forma activa o pasiva en la vida institucional del país. Asimismo, varios de ellos volvieron a empuñar las armas en 1891, sea luchando contra el gobierno de José Manuel Balmaceda (Del Canto fue el Comandante en Jefe del Ejército del Congreso) o contra las fuerzas revolucionarias.

Por otra parte, estos hombres presentaron distintas motivaciones para narrar sus vivencias durante el conflicto. Arturo Benavides Santos, por ejemplo, publicó su relato en la década de 1920, periodo marcado por una fuerte crisis institucional y en el que a su juicio el pueblo había perdido gran parte de su legendario patriotismo ${ }^{46}$, el cual pensaba reavivar con su testimonio. En otros, sobre todo los que escribieron casi al calor de los acontecimientos, días o semanas o meses después de los sucesos vividos, como Justo Abel Rosales, hacen su narración a modo de catarsis, como una forma de digerir lo vivido y asimilarlo a sus vidas. Mientras que para algunos, sobre todo cuando el relato es hecho en una edad avanzada, es la nostalgia lo que prima. Alejandro San Francisco, al realizar el estudio preliminar de las "Memorias Militares" de Estanislao del Canto en el año 2007, destacó que este oficial:

\footnotetext{
${ }^{46}$ Benavides S, A. 1929. Seis Años de Vacaciones, p.13.
} 
"En los últimos años de su vida, dedicó mucho tiempo a los recuerdos de las glorias pasadas, de los triunfos obtenidos en los campos de batalla, las victorias contra enemigos externos, Perú y Bolivia, y nacionales, los Balmacedistas [...] Sabemos que del Canto tenía interés en que su trabajo fuera publicado, que no quedara como una obra meramente personal y sin trascendencia social ${ }^{47 \prime \prime}$.

Todas estas motivaciones, demanda política, catarsis o nostalgia, influyen en cómo los combatientes-veteranos van a escribir su relato. El cual, como indicamos, siempre tendrá un carácter fragmentario, a la vez que lleno de silencios y olvidos. Siendo la primera y fundamental consecuencia emocional que se desprende de los relatos la intensidad de la experiencia bélica.

Para los hombres y también mujeres chilenas que estuvieron presentes y sobrevivieron a las campañas de la guerra, la experiencia fue única en sus vidas y los hizo distinguirse de quienes no compartieron sus vivencias. Esto posibilitó el desarrollo de profundos lazos entre ellos, los cuales escaparon a la condición social de cada uno tanto antes como tras la guerra, generándose de esta forma una comunidad emocional que compartía una visión respecto a esta y sus consecuencias. Un ejemplo de esto lo encontramos en el relato dejado por José Clemente Larraín en 1910, al justificar por qué escribió acerca de sus vivencias y las de sus compañeros:

"Cuando las épocas que sobrevienen a la vida, felices por algún motivo, van dejándonos, sentimos desconsuelo, y como deseos de retenerlas y apegarlas a nosotros, para que esa parte de nuestros días no se borre en la fragilidad de las horas que hacen el nacer y el morir, y las recordamos siempre, para que su memoria sea algo más que un recuerdo [...] Por eso obligatorio me era prestarles el vestuario que mi cariño y fuerzas tejiesen, dándoles abrigo en las páginas de este libro ${ }^{48 \prime \prime}$.

Otro caso en donde se manifiesta la tremenda importancia de la experiencia bélica, y el desarrollo de lazos profundos entre quienes vivieron la Guerra, lo encontramos en uno de los pasajes que escribió Arturo Benavides Santos en su obra "Seis Años de Vacaciones", cincuenta

\footnotetext{
${ }^{47}$ Del Canto. E. Memoria Militares. Estudio Preliminar de Alejandro San Francisco. p. XLVI. Otra motivación para dejar un relato, pero que no aparece contemplada directamente en los testimonios analizados en este artículo, es la reivindicación social y material por los servicios prestados en la Guerra. Al respecto, una delos testimonios más explícitos es el de Evaristo Sanz, quien señalo en su breve relato que: "Nuestra actual guerra con la alianza PerúBoliviana que tantos triunfos i (Sic) a tan altas glorias ha dado a nuestro querido Chile, campo fecundo de ascensos i (Sic) laureles para nuestros bravos guerreros, ha sido para mí árido desierto en que solo he encontrado cruel indiferencia i amargos desengaños". Sanz, E.1885. Hojas sueltas de mi diario de campaña, p. 94.

${ }^{47}$ Larraín. J. 1910. Impresiones y Recuerdos. p.13.

${ }^{48}$ Larraín. J. 1910. Impresiones y Recuerdos. p.13.
} 
años después del comienzo de la conflagración. En esta, el veterano relató una situación muy especial que vivió con una cantinera, las cuales eran mujeres chilenas que eran parte de los regimientos y prestaban una serie de servicios, tales como ayudar durante los combates repartiendo agua y municiones, socorriendo y aliviando a los heridos e incluso empuñando el fusil en caso de necesidad ${ }^{49}$. Durante la retirada de la expedición dirigida por Estanislao del Canto desde la sierra peruana de 1882, la mujer comenzó con dolores de parto. Benavides no menciona su nombre, solo que es la mujer de un sargento de su Regimiento, omitiendo también el nombre de este. Pero relatando que para el alumbramiento: "Su marido la había acomodado para efectuarlo en un caballo que era tirado por soldados, que voluntariamente se alternaban, cuando llegó el momento, la bajaron y la tendieron sobre algunas frazadas, se la atendió por otras mujeres, y minutos después se la volvió al caballo. Sobre la criatura no cayó nieve por cierto... solo la madre la recibía..." ${ }^{50}$.

El mismo veterano, que durante la Guerra fue un oficial de baja graduación, señaló que aproximadamente en 1910: “...yendo por la Avenida Brasil, en Valparaíso, oigo que una mujer anciana se dirige a mí, diciéndome: 'Mi tenientito, cuánto gusto tengo de verlo'... Era esa sufrida mujer... Pocas veces he dado un abrazo con más gusto..." ${ }^{51}$.

La intensidad de lo vivido durante el conflicto también se manifestó de otras maneras en los testimonios. La muerte y el recuerdo de los compañeros caídos quedaron presente para siempre en los antiguos combatientes. José Clemente Larraín dejó esto de manifiesto. En su obra se refirió a sus vivencias y las de su regimiento, el conocido "Esmeralda Séptimo de Línea". Recordó con claridad y con el dolor aún a flor de piel, resistiéndose al olvido, a sus compañeros caídos en la batalla de Miraflores, el 15 de enero de 1881. Especialmente a Luis Larraín Alcalde, quien fue herido en el combate y falleció días después de arribar a Valparaíso, el 3 de febrero del mismo año. Al respecto, escribió:

"Ah, día inicuo, cuanto nos dueles aún! Por ti jcuantos amigos y compañeros vimos morir! Sí, tan cruel fuiste, que mataste además a él...

¡Le matas, cuanto le había respetado furores mayores que el tuyo, que el subyugó valiente; y cuando le amábamos mil y mil corazones, y en su inteligencia limpia y joven brillaban cien ensueños que valían un mundo!" ${ }^{52}$.

Asimismo, las situaciones vividas en el campo de batalla, en el fragor de la lucha, quedaron grabadas a fuego en el recuerdo de los combatientes. En otro pasaje de sus recuerdos,

\footnotetext{
49 Larraín, P. 2006. La presencia de la mujer. p.169.

${ }^{50}$ Benavides Santos. 1929. Seis Años de Vacaciones. Pág. 232.

51 ídem.

52 Larraín.1910, J. Impresiones y Recuerdos, p. 355.
} 
Benavides se explaya brevemente respecto a lo que vivió durante unos momentos en plena batalla de Chorrillos, el 13 de enero de 1881. Al ir avanzando junto a sus compañeros y rebasando las trincheras peruanas, este combatiente vio cómo desde un grupo de soldados peruanos muertos: "[...] se incorpora un tanto uno de los que yacían en el suelo, que estaba casi a mis pies, que yo creía cadáver, y con una actitud que me pareció agresiva, me dirigió una mirada de odio o dolor, no lo sé, pero que nunca olvidaré! [...] Un culatazo dado por un soldado antes de poderlo impedir lo derribó." ${ }^{53}$.

Los relatos dejados por estos veteranos de la Guerra del Pacífico reflejan con claridad la intensidad de la experiencia vivida durante los combates y las campañas militares. Siendo esa intensidad la consecuencia emocional fundamental experimentada por ellos. El recuerdo de lo vivido durante la conflagración como uno de los momentos más importantes de sus vidas, la remembranza de los compañeros caídos y de las situaciones extremas quedaron para siempre en ellos. Pero en sus narraciones, de carácter fragmentario, por la imposibilidad de evocar todo lo vivido, priman los silencios y los olvidos, como se desprende de sus relatos. De acuerdo a los estudios sobre la memoria, los silencios se guardan a veces porque la experiencia vivida es tan brutal, tan traumática, que no existen ni siquiera las palabras adecuadas para expresar lo vivido. Al respecto, Elizabeth Jelin señala que el dolor sentido por lo vivido impide que este sea transmissible, privando a la víctima del recurso del lenguaje, de su comunicación ${ }^{54}$. Junto con eso, el relato no debe ir en contra de la cultura y la sociedad en la cual quien deja una narración de sus vivencias está inserto, por lo que este queda en un dilema: "O cuenta con la posibilidad de perder a un público que no quiere o no puede escuchar todo lo que quiere contar, o calla y silencia, para conservar un vínculo social con una audiencia, con el costo de reproducir un hueco y un vacío de comunicación". ${ }^{55}$ Asimismo, dado lo terrible de lo vivido, quizás es mejor dejarlo en el olvido. Jelin se refiere a ese olvido como liberador "[...] que libera de la carga del pasado para así poder mirar al futuro. Es el olvido necesario en la vida individual" ${ }^{\prime 56}$.

Todo esto denota que quienes nos dejaron un relato de sus vivencias en la guerra hicieron un profundo proceso de selección, tanto por la motivación para escribir como por aquellas cuestiones podían que eran reproducibles o que ellos mismos prefirieron no narrar. Pero a pesar de esto, la intensidad de la experiencia bélica quedó como una marca en sus relatos, y como se desprende de estos, como la consecuencia emocional fundamental experimentada por los combatientes chilenos de la Guerra del Pacífico.

\footnotetext{
53 Benavides Santos, A. 1929. Seis Años de Vacaciones, p. 129.

54 Jelin, E. 2002. Los trabajos de la memoria, p. 96.

55 Ibíd. p.82.

${ }^{56}$ Ibíd. p. 32
} 


\section{Las emociones durante el conflicto en desarrollo}

La intensidad de la experiencia bélica que se desprende de lo relatado por los tres veteranos que indicamos en el punto anterior es manifestada décadas después de la Guerra. En el caso de José Clemente Larraín su narración es publicada veinte años después de esta, y en el de Arturo Benavides Santos y Estanislao del Canto llega casi a los cincuenta años, por lo que se trata de consecuencias emocionales que estuvieron presentes en toda la vida de estos sujetos, yendo mucho más allá del conflicto. A continuación nos acercaremos a consecuencias emocionales de diversa índole, que fueron manifestadas durante el propio conflicto y que en este mismo afectaron a miembros de la comunidad emocional compuesta por los combatientes chilenos de la Guerra del Pacífico. Las consecuencias emocionales a las que nos acercaremos son un aparente caso de suicidio y otro que efectivamente se realiza, a las profundas impresiones experimentadas por un combatiente tras una batalla y al colapso nervioso de un oficial de alto rango en pleno combate. Eventualmente, deben existir muchas más consecuencias emocionales relatadas en los testimonios. Pero para efectos de esta investigación nos ceñimos a estos cuatro casos, ya que en ellos es posible apreciar con claridad la fragmentación, el silencio y el olvido. En dos de los tres casos la consecuencia emocional no es experimentada por quien deja relato, sino que por un tercero. Mientras que en el último es el propio combatiente quien las experimenta, siento su relato escrito solamente algunas semanas tras los combates en los que se vio involucrado, lo cual marca una diferencia significativa con los testimonios del primer apartado.

El caso de un aparente suicidio es relatado en el "Diario de Campaña. Recuerdos íntimos de la Guerra del Pacífico (1879-1884)", de Alberto del Solar Navarrete (1859-1921), quien tras la Guerra fue escritor y diplomático, a la vez que ampliamente conocido por ser su figura uno de los personajes principales de la novela histórica de Jorge Inostroza "Adiós al Séptimo de Línea ${ }^{57 "}$ a mediados del siglo XX. En la narración dejada por del Solar, quien durante la guerra tuvo el rango de subteniente, relató que tras la batalla de Tacna (26 de mayo de 1880) se le concedió permiso para volver durante un breve periodo de tiempo a Chile, realizando el viaje a bordo de un transporte lleno de soldados heridos o enfermos. Un grupo de ellos se encontraba en la cubierta del barco, hacia la proa, "[...] hallábanse tendidos treinta o cuarenta de esos infelices, resguardados apenas de la intemperie y de sol por una tienda de lona" ${ }^{58}$. Entre ellos, el autor destaca al cabo Casimiro, sin dar mayores datos acerca de él, pero señalando que se encontraba: "[...] horriblemente maltratado por la fractura de una pierna y la amputación reciente del brazo izquierdo; todo ello ocasionado por cuatro o cinco balazos

\footnotetext{
${ }^{57}$ Inostroza, J. 1955. Adiós al Séptimo de Línea. Santiago, Zig- Zag.

${ }^{58}$ Del Solar, A. 1967. Diario de Campaña. p. 183.
} 
recibidos con porfiada y cruel fatalidad en el heroico asalto a las fortaleza de Arica." ${ }^{59}$ Según del Solar, por solicitud del propio cabo: [...] se le había acondicionado sobre cubierta, "en la carpa de los sobrantes", como decían en su lenguaje seco los oficiales encargados de su custodia" ${ }^{60}$. Constantemente era visitado por oficiales, compadecidos por la condición en que se encontraba. Esto hasta que días después sobrevino una fuerte tormenta, en la cual debido a los bamboleos del barco los heridos y enfermos sufrieron mucho. A la mañana siguiente tras la tormenta:

"[...]un grupo agitado y bullicioso compuesto por un puñado de marineros y sirvientes de abordo mezclados con los enfermos que, medio incorporados sobre sus lechos, con la palidez del terror en el semblante, indicaban con señas las bordas del buque y las olas del mar a los curiosos que iban aproximándose, denotaba que algo extraño ocurría y ocupaba la atención general.

Llevado a mi vez por la curiosidad, me dirigí hacia la proa y abordando a un grumete:

-¿¿Qué ocurre?', le pregunté.

- 'Una desgracia irreparable mi teniente', me contestó con voz sombría. 'El cabo Casimiro ha desaparecido anoche, en medio de la tormenta, barrido, sin duda por una ola. O sino' agregó pensativo, 'como sufría atrozmente, desesperado, quizás ha debido en un acceso de delirio arrojarse al mar $[\ldots]^{61}$.

Del Solar, sin explayarse en mayores detalles, y no mencionando nombres da a entender que el cabo debió suicidarse al no aguantar más el sufrimiento y la agonía de sentirse y verse mutilado. Las heridas y el dolor, más el verse sin su brazo debieron haberlo llevado a tomar aquella decisión, siendo esta una consecuencia emocional causada por la guerra misma. Que el sufrimiento causado por el conflicto lleve a provocar que un soldado se quite la vida es algo que también recordó Diego Dublé Almeida (1841-1922) en su “Diario de Campaña. Lo que yo he visto". En las penosas marchas realizadas por el Ejército chileno antes de la batalla de Tacna, el asistente del hermano de Dublé Almeida (Baldomero, quien falleció por sus heridas tras la batalla de Chorrillos), sufrió espantosamente por la sed, y al quedarse atrás en la marcha no aguantó más y se descerrajó un tiro: “[...] sentimos la detonación de un tiro de fusil, lo que nos alarmó creyendo haber caído entre enemigo. Al volver la cabeza hacía atrás, vimos al asistente de mi hermano [...] El soldado estaba muerto; tenía el cráneo despedazado;

\footnotetext{
59 Ídem.

${ }^{60}$ Ibíd. Pág. 184

${ }^{61}$ Ibíd. 188-189.
} 
la bala le había entrado por debajo de la barba. El infeliz se había suicidado con su propio fusil. La sed lo había vuelto loco" ${ }^{62}$.

En su narración Dublé Almeida no vuelve a referirse sobre este caso, ni tampoco menciona el nombre del soldado que se quita la vida, no realiza mayores reflexiones, aunque señala que al llegar a un depósito de agua comentó con sus compañeros: "[...]aquel, para nosotros, doloroso accidente ${ }^{63 \prime \prime}$.

Otras consecuencias emocionales se manifiestan en el propio campo de batalla, dejando una huella profunda en el individuo. En un espacio caótico, con poca visibilidad, entre los gritos de los heridos y la confusión, los nervios parecen llegar hasta el colapso. Esto es lo que relata Estanislao del Canto en su narración acerca de lo que vivió durante la batalla de Chorrillos. Al comenzar este combate, las tropas chilenas encontraron grandes dificultades para avanzar hacia el Morro Solar, el cual se encontraba fuertemente fortificado. Ante esto, es enviado a la batalla el regimiento Valparaíso, que era parte de las tropas chilenas de reserva. Del Canto, en ese entonces comandante del regimiento "Segundo de Línea", recordó en su relato que los soldados porteños abrieron fuego sobre sus tropas al confundirlas con peruanos. Arriesgando su vida, este ya experimentado oficial levantó un pañuelo blanco para que los soldados cesasen los disparos, y cuando estos pararon: "[...] reconocí que era el regimiento Valparaíso, que mandaba el comandante don José María Marchant; y a quien me dirigí para hacerle presente la equivocación sufrida. Entonces Marchant me dijo tomándose el pelo: "Cantito, por Dios, ¿con que son compañías del $2^{\circ}$ sobre las que hacemos fuego? $Y$ habiéndole contestado afirmativamente, observé que se quedó en las manos con cabellos que se había arrancado nerviosamente por la equivocación sufrida" ${ }^{64}$.

Al igual que en los casos anteriores, Del Canto no se explaya más respecto a lo vivido en aquel momento, guardando silencio, y quizás también, tratando de olvidar parte de lo experimentado. Quien sí se extiende bastante en relación a su experiencia y no a la de un tercero, pero de igual forma guarda silencio, es Justo Abel Rosales (1855-1896) con lo vivido al anochecer del 15 de enero de 1881 finalizada la batalla de Miraflores. Este combatiente perteneció al regimiento "Aconcagua" y su única experiencia en combate fue durante las batallas de Chorrillos y Miraflores. Dotado desde joven de una gran afición literaria, escribió en diarios y tras la guerra una serie de libros (también fue funcionario público y Archivero de la Biblioteca Nacional). Durante el conflicto llevó Rosales un diario de campaña en el que escribió sus impresiones diarias, al igual como lo hizo del Solar o Dublé Almeida. Su diario

\footnotetext{
62 Dublé. A. 2008. Diario de mi Campaña. p. 8.

63 Ídem.

${ }^{64}$ Del Canto, E. 2004. Memorias Militares. p. 125.
} 
recién fue publicado en 1984, gracias a Juan Luigui Lemus (1928-2011), quien rescató los recuerdos de este combatiente desde la colección Fondos Varios del Archivo Nacional.

Junto con relatar la vida cotidiana en los campamentos militares, la rutina, los paisajes, los chismes y el denodado consumo de alcohol en la tropa, Rosales también narró en su diario sus vivencias en las batallas por Lima, a solo unos pocos días después de ocurridas, cuestión que marca una diferencia sustancial con la mayoría de los testimonios, los cuales son escritos años o décadas después. En el relato de Rosales, hay una situación que denota haber dejado una fuerte marca en su vida. En la noche, tras la batalla de Miraflores, él tuvo que pasar camino a su regimiento por el campo de batalla junto algunos soldados dispersos. Rosales mismo recuerda que aquel paso fue "[...] una experiencia dolorosa para mí y la recordaré siempre" ${ }^{65}$. Este combatiente, que tenía el rango de subteniente, debió avanzar en la oscuridad entre los cadáveres y heridos que clamaban por ayuda sin poder auxiliarlos: "[...] a la distancia oíamos estos lamentos al sentirnos marchar: Por amor de Dios vengan a llevarme que me muero, y esto con voz tan lastimera que partía el alma. Otros más alentados gritaban como un centinela: 'Quién vive'. Los soldados respondían: 'Chile', ¿Quién está ahí?, 'Yo hermanito', respondía la misma voz, 'sáquenme de este lugar, que ya no puedo más'”66.

Entre los caídos había personas cercanas a Rosales, quien en su relato expresó la impotencia que sintió al no poder hacer nada por ellos. A la vez que reflexionó sobre del horror que presenció:

"Nos inclinábamos a reconocer al moribundo y era algún conocido del Aconcagua o del Coquimbo o del Naval [regimientos], iQue tendal de gente! iCuántos hombres sanos y robustos pocas horas antes, y ahora yertos y helados como un mármol! ¿Qué auxilio podíamos prestar a tanto infeliz que nos clamaba protección, en medio de ese campo oscuro que atravesábamos, sin rumbo fijo y sin saber hasta dónde iríamos a llegar? Yo sufría, tanto como los mismos desgraciados que alfombraban esos potreros" ${ }^{\prime 67}$.

En su relato, este combatiente, que escribió sin el ánimo de que sus vivencias fuesen conocidas por un público, se permitió dejar espacio para recordar a uno de los heridos que encontró en su camino. Siendo este probablemente uno de los recuerdos más duros que quedaron en su memoria, dejando una profunda consecuencia emocional en él, tanto por la emoción e impotencia que experimentó. Sin embargo, es posible deducir que no se sinceró completamente en su narración, guardando silencios:

\footnotetext{
${ }^{65}$ Rosales. J. 1984. Mi Campaña al Perú, p. 220.

${ }^{66}$ Ibíd., p. 221

67 ídem.
} 
"Casi lloré de pena cuando al reconocer a uno que apenas hablaba me dijo: 'Soy Rubio de la 2a Compañía'. Este Rubio era uno de los más antiguos del regimiento (Aconcagua) y como militar muy bueno. Tendría unos 16 años. Me suplicó que lo llevara a una ambulancia y agregó: 'hágame el favor mi subteniente, de llevarme de aquí, porque estoy muy mal herido'; digo que este pobre niño me llenó de amargura la garganta, como si me hubieran dado de beber hiel ¡Cuánto sentí haberlo encontrado!"68.

Tras esta experiencia, Rosales no vuelve a referirse a ella en su diario. Quizás no desea enfrentarla o volver a rememorarla, tratando de dejarla en el olvido y guardando silencio respecto a cómo asumió lo vivido en los días siguientes. A los pocos meses, tras la caída de Lima y el comienzo de la ocupación chilena, renuncia a su comisión y vuelve a Chile para nunca más empuñar las armas. En 1891, tras la Guerra Civil, fue acusado de Balmacedista y debió dejar su cargo en la Biblioteca Nacional, falleciendo en 1896, sumido en la pobreza y el alcoholismo.

\section{Conclusiones}

Este artículo sostiene que en algunos de los relatos dejados por combatientes chilenos de la Guerra del Pacífico y que han sido publicados, quedaron plasmadas las consecuencias emocionales que experimentaron ellos y sus compañeros de tropa durante el conflicto y el resto de sus vidas. Estas consecuencias se explican porque quienes dejaron una narración de sus vivencias son parte de una misma comunidad emocional, aquella compuesta por los combatientes del "Ejército del Norte" durante la guerra, no por periodistas, sacerdotes u otros testigos, los cuales aceptaban emociones iguales o parecidas. Para acercarnos a las consecuencias emocionales, nos apoyamos en los estudios sobre la memoria, ya que estos permiten reconocer la fragmentación, los silencios y los olvidos presentes en los relatos.

Se establecieron dos apartados, en el primero se buscó resaltar la intensidad de la experiencia bélica que tuvieron los combatientes-veteranos. Esto, como la consecuencia emocional básica plasmada en los testimonios dejados por ellos. Al respecto, de acuerdo a los relatos, se denota que el recuerdo de lo vivido, de los compañeros caídos y las situaciones vividas guardaron un lugar especial en sus vidas, pero este recuerdo está marcado por fragmentos, silencios y olvidos. Esto se explica tanto porque sus relatos iban dirigidos a un público ávido de conocer acerca de sus vivencias como porque la experiencia bélica había sido tan dura que era preferible no narrarla, manteniendo silencios respecto a fragmentos de esta y dejándolas mejor en el olvido.

68 Ídem. 
En el segundo apartado, nos acercamos a las consecuencias emocionales vividas en la guerra misma o en el campo de batalla. Indicamos cuatro casos, dos de suicidios (uno aparente), uno de un colapso nervioso y otro relativo a las profundas impresiones experimentadas al cruzar el campo de batalla tras la lucha. En tres de los cuatro pasajes escritos por los combatientes vemos que se refieren a otros y no a ellos mismos como quienes experimentan consecuencias emocionales, siendo solamente en el relato de Justo Abel Rosales en donde es el propio autor que las experimenta. Asimismo, en las cuatros narraciones, la fragmentación, los silencios y los olvidos aparecen, a la vez que la empatía con los compañeros que se quitan la vida o sufren tanto por sus heridas como por lo que han vivido. Cuestión que los muestra como miembros de una misma comunidad emocional. Es interesante, y queda como propuesta para investigaciones posteriores, acercarse a las eventuales patologías mentales que hubiesen desarrollado los combatientes chilenos tanto durante como después de la Guerra. Un trabajo interdisciplinar, apoyando en la noción de comunidad emocional, podría acercarse a otras fuentes y hacer el análisis. Después de todo, ya en el mundo occidental en la década de los setenta del siglo XIX había estudios sobre los efectos de la guerra, como es el publicado por Jacob M. Da Costa en 1871. Este médico evaluó a 300 combatientes de la guerra civil estadounidense que presentaban lo que él llamó el "corazón irritable", el cual era atribuido a factores psicológicos. A su vez, durante aquel conflicto fue descrito otro fenómeno que experimentaban los combatientes, ya que hubo soldados jóvenes con pensamientos obsesivos sobre su hogar, que mostraban además una apatía total, falta de apetito, diarrea y fiebre, siendo diagnosticados con "nostalgia"69. Ante esto, eventualmente las fuentes archivísticas deben entregar información respecto a los fenómenos mencionados y también respecto a cómo actuaron las instituciones de la época frente a estos.

Otra cuestión que cabe señalar, y que queda pendiente, es que en los testimonios citados en este trabajo no se encuentran reflexiones de soldados rasos. Con lo que queda abierta la pregunta ¿hubo una comunidad emocional propia de los combatientes subalternos? Si es así ¿Cuáles son las diferencias respecto de los testimonios analizados? El análisis de otras fuentes puede darnos pistas en el futuro ${ }^{70}$. Debe considerarse que Bárbara Rosewein reconoce la posibilidad de que hayan comunidades emocionales que se interrelacionen de manera compleja $^{71}$. Finalmente, al entrar en el estudio de las consecuencias emocionales que nacieron

\footnotetext{
69 Ruiz Vargas, J. 2006. "Trauma y memoria de la Guerra Civil y de la dictadura franquista". Hispania Nova. En HISPANIA NOVA. Revista de Historia Contemporánea. $\mathrm{N}^{\circ} 6$.

${ }^{70}$ A modo de ejemplo, cabe señalar que en el Fondo Vicuña Mackenna del Archivo Nacional existen miles de cartas que fueron enviadas a este Historiador y que aún no han sido analizadas en toda su magnitud. Solo autores como Carmen Mc Evoy han estudiado una pequeña porción de estas.

${ }^{71}$ Medina Brenner, L. 2015. “Comunidades emocionales”. p.207.
} 
de la experiencia bélica de los combatientes chilenos de la Guerra del Pacífico, cabe señalar que entramos en un terreno en el que cabe hacer aún más investigación, siendo este solo un breve ejercicio de lo que nos puede aportar al conocimiento esta Guerra, alejado de los estudios diplomáticos, políticos, y también en parte de los estudios sociales y culturales que se han realizado hasta ahora. Entrando así a un espacio profundo, sórdido, pero que es necesario para entender el horror que significó el conflicto visto desde abajo, en primera persona y como destrozó mentes y cuerpos, tanto en el campo de batalla como más allá.

\section{Bibliografía}

\section{Artículos de Revista}

Chaupis, J. 2015. "Guerra del Pacífico y Construcción de la Justicia: los procesos penales en Lima durante la ocupación chilena", en Revista de Historia y Geografía N 33, Santiago, pp. 63-82.

Chaupis, J. 2015. "Los textos escolares en conflicto con la subalternidad: la Guerra del Pacífico en las Aulas", en Diálogo Andino, №48, Arica, pp. 99-108.

Ibarra, P. 2007. "Un testimonio sobre la entrada del Ejército chileno a Lima (Enero de 1881)", en Cuadernos de Historia, $\mathrm{N}^{\circ} 26$, Santiago, pp. 171-186.

Jelin, E. 2001. "Historia, memoria social y Testimonio o la legitimidad de la palabra", en Iberoamericana, año I, Nº1, Berlin, pp. 87-98.

Ibarra, P. 2007. "Un testimonio sobre la entrada del Ejército chileno a Lima (Enero de 1881)", en Cuadernos de Historia, N²6, Santiago, pp. 171-186.

Medina, L. 2015. "Comunidades emocionales: hacia la apertura de la historia de las emociones", en Historia y Grafía, año 22, №45, Ciudad de México, pp. 204-213.

Moscoso, J. 2015. "La Historia de las Emociones ¿De qué es Historia?", en Vínculos de Historia, ํ4, Ciudad Real (España), pp. 15-27.

Pampler, J. 2014. "Historia de las Emociones: Caminos y retos", en Cuadernos de Historia Contemporánea, Vol. 36, Madrid, pp. 17-29.

Rivera, P. 2016. "Fantasmas de rojo y azul. Los saqueos de las tropas chilenas en la guerra del Pacífico", en Anuario Colombiano de Historia Social y de la Cultura, Vol. 43, N²1, Bogotá, p. 263-293.

Rubilar, M. 2015. “'La Prusia Americana': prensa argentina e imaginario internacional de Chile Durante la Guerra del Pacífico", en Revista de Historia y Geografía, N³3, Santiago, pp. 83-121.

Ruiz, J.M. 2006. "Trauma y memoria de la Guerra Civil y de la dictadura franquista", en Hispania Nova, Revista de Historia Contemporánea, Nº, Madrid, pp. 2-39.

Tapia, C. 2017. "La política chilena en la postguerra del Pacifico: poder, influencia y relaciones con Ecuador", en Revista Historia Crítica, №64, Bogotá, pp. 121-139.

Veliz, C. 2015. "Bajo la tienda (1958): la representación subalterna del "roto" como fundamento de la nacionalidad para el siglo XIX chileno", en Diálogo Andino, №48, Arica, pp. 7-17.

Wallach, J. 2014. “¿Después de la Historia?”, Rey Desnudo, Revista de libros, año II, N4, Buenos Aires, pp. 6-30.

Zaragoza, J.M. 2013. "Historia de las emociones una corriente historiográfica en expansión", en Revista de Historia de la Medicina y de las Ciencias, vol. 65, №1, CSCIC, Madrid, pp. 2-11. 


\section{Capítulos de Libros.}

Cid, G. 2011. "Arte, Guerra e Imaginario Nacional: la Guerra del Pacífico en la pintura de Historia chilena, 1879-1912", en Donoso, C. y Serrano, G. (eds.), Chile y la Guerra del Pacífico, Santiago, Centro de Estudios Bicentenario, pp. 75-113.

Ibarra, P. 2018. "Narro lo que vi': la Guerra del Pacífico en primera persona”, en Chaupis, J. y Tapia, C. (eds.), La Guerra del Pacífico 1879-1884: ampliando miradas en la historiografía chileno- peruana, Santiago, Legatum Editores, pp. 220 y 223.

Rubilar, M. 2017. "Prensa, opinión pública y política exterior de Chile durante la Guerra del Pacífico (1879-1883)", en Díaz, A., González, S., Ruz, R., Salazar, P. (eds.), WAYRA. Nuevos vientos en la historiografía chilena, Arica, Ediciones Universidad de Tarapacá, pp. 321-336.

Rubilar, M. 2018. "El bárbaro del Pacífico: imaginario discursivo sobre Chile en la prensa de Buenos Aires durante la Guerra del Pacífico 1879-1881", en Chaupis, J. y Tapia, C. (eds.), La Guerra del Pacífico 1879-1884: ampliando miradas en la historiografía chileno- peruana, Santiago, Legatum Editores, pp. 67-92.

Rubilar, M. 2018. "iLos hijos del Biobío en pie de guerra!: Iglesia, prensa y compromiso ciudadano durante la Guerra del Pacífico (1879-1881)", en Ibarra, P. y Morong, G. (eds.), Relecturas de la Guerra del Pacífico. Avances y perspectivas, Santiago, Editorial Universidad Bernardo O’Higgins, pp. 49-72.

Tapia, C. 2018. "Intereses, rivalidades y consecuencias. Una reflexión sobre la guerra en el Pacífico Sudamericano", en Chaupis, J. y Tapia, C. (eds.), La Guerra del Pacífico 1879-1884: ampliando miradas en la historiografía chileno-peruana, Santiago, Legatum Editores, pp. 19-40.

Tapia, C. 2018. "La construcción de la política exterior chilena en el contexto de la guerra y postguerra del Pacífico", en Ibarra, P. y Morong, G. (eds.), Relecturas de la Guerra del Pacífico. Avances y perspectivas, Santiago, Ediciones Universidad Bernardo O’Higgins, pp. 145-170.

\section{Libros}

Castagneto, P. 2007. Eloy Caviedes: El combate de lquique, Viña de Mar, Ediciones Altazor.

Castagneto, P. 2014. Eloy Caviedes. Cartas de la escuadra: la campaña naval de 1879 relatada por el corresponsal de "El Mercurio", Santiago, Red Internacional del Libro.

Cavieres, E. y Chaupis, J. (eds.). 2015. La Guerra del Pacífico en perspectiva histórica: reflexiones en pasado y en presente, Antofagasta, Universidad de Tarapacá.

Chaupis, J. y Tapia, C. (eds.). La Guerra del Pacífico 1879-1884: ampliando miradas en la historiografía chileno- peruana, Santiago, Legatum Editores.

Donoso, C. y Serrano, G. (eds.). 2011. Chile y la Guerra del Pacífico, Santiago, Centro de Estudios Bicentenario.

Jelin, E. 2001. Los trabajos de la memoria, Madrid, Siglo XXI Editores.

Ibarra, P. 2017. La guerra en cautiverio. Los prisioneros de la Guerra del Pacífico (1879-1884), Santiago, Legatum Ediciones.

Ibarra, P. y Morong, G. (eds.). 2018. Relecturas de la Guerra del Pacífico. Avances y perspectivas, Santiago, Ediciones Universidad Bernardo O'Higgins.

Inostroza, J. 1955. Adiós al Séptimo de Línea, Santiago, Zig-Zag.

Larraín, P. 2006. La presencia de la mujer chilena en la Guerra del Pacífico, Santiago, Universidad Gabriela Mistral. 
Marchant, R. 2004. Testimonios de un capellán castrense en la Guerra del Pacífico, estudio preliminar de Paz Larraín y Joaquín Matte Varas, Santiago, Centro de Estudios Bicentenario.

Mc Evoy, C. 2010. Armas de persuasión masiva: retórica y ritual en la Guerra del Pacífico, Santiago, Centro de Estudios Bicentenario.

Mc Evoy, C. 2013. Guerreros Civilizadores. Política, Sociedad y Cultura en Chile durante la Guerra del Pacífico, Santiago, Ediciones Universidad Diego Portales.

Mc Evoy, C. 2016. Chile en el Perú. La ocupación a través de sus documentos, 1881-1884, Lima, Fondo Editorial del Congreso del Perú.

Méndez, C. 2009. Héroes del Silencio: los veteranos de la Guerra del Pacífico (1884-1924), Santiago, Centro de Estudios Bicentenario.

Méndez, C. 2009. Desierto de esperanzas: de la gloria al abandono. Los veteranos chilenos y peruanos de la guerra del 79, Santiago, Centro de Estudios Bicentenario.

Méndez, C. 2013. Dolor y olvido: los ex combatientes bolivianos de la Guerra del Pacífico, Santiago, Centro de Estudios Bicentenario.

Rabinovich, A. 2017. Anatomía del pánico: La batalla de Huaqui, o la derrota de la Revolución (1811), Buenos Aires, Editorial Sudamericana.

Rodríguez, S. 1986. Problemática del soldado durante la Guerra del Pacífico, Santiago, Edimpres.

Rosewein, B. 2006. Emotional Communities in the early middle ages. Ithaca, NY., Cornell University Press.

Ruz, F. (comp). 1979. Guerra del Pacífico. Memorias de Jose Francisco Vergara (1883-1889). Diario de

Campaña de Diego Duble Almeida (1841-1922), Santiago, Editorial Andrés Bello.

Satter, W. 1986. Chile and de War of the Pacific, Lincoln. University of Nebraska

Satter, W. 2007. Andean Tragedy: Fighting the War of the Pacific (1879-1884), Lincoln, University of Nebraska. Obra traducida el año 2016 como Tragedia Andina: La lucha en la Guerra del Pacífico (1879-1884), Santiago, Centro de Investigaciones Barros Arana.

\section{Testimonios de combatientes}

Benavides Santos, A. 1929. Seis años de Vacaciones. Recuerdos de la Guerra del Pacífico. 1879-1884, Santiago, Imprenta Ahumada.

Chaparro, G. 1910. Recuerdos de la Guerra del Pacífico, Estado Mayor General, Santiago.

Del Canto, E. 2004. Memorias Militares, Edición y Estudio preliminar de Alejandro San Francisco, Santiago, Centro de Estudio Bicentenario.

Del Solar, A. 1967. Diario de campaña: recuerdos íntimos de la Guerra del Pacífico: 1879- 1884, Buenos Aires, Editorial Francisco de Aguirre.

Dublé, D. 1968. "La jornada de Tacna. Un cuadro de campaña", en Revista Chilena de Historia y Geografía, N¹36, Santiago, pp. 125-168.

Dublé, D. 2011. "Diario de las Campañas al Perú y Bolivia. 1879-1884. Lo que yo he visto", en Cuadernos de Historia Militar, $N^{\circ} 7$, Santiago, pp. 23-92.

Dublé, D. 2012. “Diario de las Campañas al Perú y Bolivia. 1879-1884. Lo que yo he visto. Segunda Parte", en Cuadernos de Historia Militar, Santiago, N 8, pp. 7-60.

Gutiérrez, H. y Quiroz, A. 1976. Dos soldados en la Guerra del Pacífico, Buenos Aires, Editorial Francisco de Aguirre.

Ibarra, M. 1985. Campaña de la Sierra: La Concepción - una aventura, La Serena, Universidad de La Serena. 
Larraín, J. 2007. Impresiones y recuerdos sobre la Campaña al Perú y Bolivia, Santiago, Centro de Estudios e Investigaciones Militares.

Lehnert, R. y Lira, J. 2010. Vivencias de un héroe: Capitán José Ramón Lira en la Guerra del Pacífico, Antofagasta, Instituto de Investigaciones Antropológicas.

Olid, A. 1999. Crónicas de Guerra: relatos de un ex combatiente de la Guerra del Pacífico y la Revolución de 1891, Santiago, Ril Editores.

Parvex, G. 2014. Un veterano de tres guerras. Recuerdos de José Miguel Varela, Santiago, Academia de Historia Militar.

Rosales, J. 1984. Mi Campaña al Perú (1879-1881), Concepción, Universidad de Concepción.

Sanz, E. 1883. Hojas sueltas de mi diario de campaña, o reminiscencias de la Guerra del Pacífico: 1879, Santiago, Imprenta de la Librería Americana

Silva, G. 1926. Memorias del veterano, Santiago, "La Economía".

Urquieta, A. 1907. Recuerdos de la vida en campaña en la Guerra del Pacífico, Santiago, Escuela Talleres "Gratitud Nacional".

Venegas, L. 1885. Sancho en la Guerra: Recuerdos de la campaña del Ejército al Perú y Bolivia, Santiago, Imprenta Victoria. 